\title{
Flood risk assessment: concepts, modelling, applications
}

\author{
G. Tsakiris \\ Centre for the Assessment of Natural Hazards and Proactive Planning, School of Rural and Surveying Engineering, \\ National Technical University of Athens, Athens, Greece
}

Correspondence to: G. Tsakiris (gtsakir@central.ntua.gr)

Received: 6 November 2013 - Published in Nat. Hazards Earth Syst. Sci. Discuss.: 14 January 2014

Revised: 21 March 2014 - Accepted: 21 April 2014 - Published: 28 May 2014

\begin{abstract}
Natural hazards have caused severe consequences to the natural, modified and human systems in the past. These consequences seem to increase with time due to both the higher intensity of the natural phenomena and the higher value of elements at risk. Among the water-related hazards, flood hazards have the most destructive impacts. The paper presents a new systemic paradigm for the assessment of flood hazard and flood risk in the riverine flood-prone areas. Special emphasis is given to the urban areas with mild terrain and complicated topography, in which 2-D fully dynamic flood modelling is proposed. Further, the EU flood directive is critically reviewed and examples of its implementation are presented. Some critical points in the flood directive implementation are also highlighted.
\end{abstract}

\section{Introduction}

Natural hazards vary in magnitude and intensity in time and space. Under certain conditions and influenced by triggering factors, they may cause loss of life, destroy infrastructures and properties, impede economic and social activities and cause destruction of cultural heritage monuments and the environment.

It should be stressed that, during the last few decades, natural hazards have been the cause of the loss of hundreds of thousands of human lives and for damage and losses of billions of euros around the world. Just in the period 1974-2003 more than two million people lost their lives due to natural hazards (Guha-Sapir et al., 2004).

Among the most destructive natural hazards are floods caused by river overflows, flash floods in the cities, and coastal floods in the coastal areas. The severe floods in central Europe during the last decade led the European Union to set in force the new Flood Directive 2007/60 which can be characterised as an innovative paradigm for the defence against floods.

It is the purpose of this overview to review the advances in flood risk assessment both from the scientific and professional point of view. In this context, the paper starts with clarification of the definitions of the key determinants, and proposes a new systemic framework for risk assessment customised for the above types of floods. Then, it presents in brief the new EU flood directive, concentrating on the urban areas with mild terrain. Finally, it highlights some important critical points which should be addressed based on the latest scientific findings, which will result in a detailed modelling of floods and give more reliable flood risk maps and plans.

\section{From hazard to risk: a systemic approach}

Although the terminology for natural risk assessment is not unique, in this paper the definitions of the most important terms are given as adopted at the Centre of the Assessment of Natural Hazards and Proactive Planning of the National Technical University of Athens. These definitions were adopted after a long debate among scientists of different disciplines who are acknowledged for their contributions.

Thus, a hazard is defined as a source of potential harm, a situation with the potential to cause damage or a threat/condition with the potential to create loss of lives or to initiate a failure to the natural, modified or human systems (Tsakiris, 2007b). A hazard can occur in different times with different magnitudes/intensities. It can be, therefore, described by a time series $H(t)$. The nature of $H(t)$ is stochastic in general. However, in certain cases, it can also be regarded as a random process if the cause is totally natural. In most cases, however, some deterministic influence can be 
caused by triggering factors which initiate the hazard occurrence or influence its magnitude.

If $H(t)$ is a totally random process, the hazard events can be described by a theoretical probability density function (PDF, $f(x)$ ). Then, the probability of occurrence or the return period of the hazardous phenomenon with certain characteristics can be estimated following conventional frequency analysis.

A very useful statistical quantity for assessing the overall destructive activity of a hazardous phenomenon is the average or annualised hazard as proposed by Tsakiris $(2007 \mathrm{a}, \mathrm{b})$. The expected value $E(D)$ and the variance $\operatorname{Var}(D)$ are written as

$$
E(D)=\int_{0}^{\infty} x \cdot f_{D}(x) \mathrm{d} x
$$

$\operatorname{Var}(D)=\int_{0}^{\infty} x^{2} \cdot f_{D}(x) \mathrm{d} x-(E(D))^{2}$,

where $D$ is the anticipated annualised damage or loss in monetary units, $f_{D}(x)$ is the PDF and $x$ is the sum of potential consequences of the phenomenon with a certain probability of occurrence (unprotected system).

The average hazard, although potential (not real), gives a representative measurement on the overall threat of the natural hazard in question. Therefore, it gives information on the degree of the hazard-prone area, as compared with other areas suffering from the same hazard, by estimating the potential consequences on the affected unprotected system. Needless to say, the variance (or the standard deviation) can give an estimate of the range of potentially expected losses/damage.

This type of quantification of hazard has been questioned by several scientists with the thesis that hazard is a potential threat and cannot be estimated through the possible damage. This opinion is also followed by the EU flood directive in which the flood hazard is quantified by the map of inundation depths of the affected area caused by a flood with certain characteristics.

Returning to the terminology adopted in this paper, the quantification of the effects of a hazard event is always based on the assumption of a totally unprotected system which is affected by this hazard. In reality, all affected systems have a level of protection ranging from absolutely minimal to a high-level protection. The degree of protection can be represented by the term of vulnerability.

The vulnerability of a certain element towards a certain natural hazard can be defined as a measurement of the degree of susceptibility to damage from this hazardous phenomenon or activity. The concept of vulnerability can be also attributed to an entire system, although it is obvious that the elements of the system may exhibit differential vulnerability.
The vulnerability of a system exposed to a certain natural hazard is dependent mainly on the degree of exposure, the condition of the system (i.e. its capacity to withstand), the magnitude of the phenomenon and the "social factor" which represents the responsiveness and the effectiveness of the people to deal with the abnormal conditions caused by the hazard occurrence. Needless to say, all these factors are to some extent interrelated and their composite effect on the vulnerability may be multiple.

Finally, the term risk of an element is defined as "the sum of expected losses and damage of any kind due to a particular natural phenomenon, as function of the natural hazard and the vulnerability of the element at risk" (UNDRO, 1991). In practical terms, risk is the real threat to an element (or a system) given its vulnerability towards the phenomenon. Therefore, risk, as adopted in this study, is measured in monetary units or any other unit of damage/losses.

It should also be mentioned, however, that risk has different meanings in various disciplines. In some cases, it is defined as the probability of occurrence of an adverse event during a number of years, and in others, as the probability that an external forcing factor exceeds the capacity or the resistance of the system leading to a failure (e.g. Hashimoto et al., 1982; Nicolosi et al., 2007).

In analogy to the average hazard, the average risk, $R(D)$, can be written mathematically:

$$
R(D)=\int_{0}^{\infty} x \cdot V(x) \cdot f_{D}(x) \mathrm{d} x,
$$

where $x$ is the potential consequence anticipated by a certain hazard with magnitude corresponding to a certain probability of occurrence. The PDF of $x$ is $f_{D}(x)$, and $V(x)$ is the vulnerability function, expressed as a function of the remaining losses when compared with the totally unprotected element/system. For simplicity, $V(x)$ is a function taking values between 0 and 1 , with 0 meaning totally protected and 1 meaning totally unprotected element/system.

For illustration purposes, Fig. 1 presents the vulnerability of a system as function of the magnitude of the hazardous phenomenon (e.g. maximum flood discharge). The initial curve shows that the vulnerability of the system is 0 up to a certain low magnitude of the phenomenon $\left(Q_{1}\right)$ and becomes 1 if the magnitude exceeds a high value $\left(Q_{2}\right)$. This means that the system becomes totally unprotected for magnitudes higher than $Q_{2}$. If the system is improved by several measures and structures, it can withstand higher magnitudes of the phenomenon. This is shown by the shift to the new vulnerability curve (improved) for which both the lower- and higher-magnitude values are shifted to the right. Therefore, as can be deduced from Fig. 1, for the same magnitude of the phenomenon the improved system exhibits lower vulnerability.

The concept of vulnerability can be also attributed to an entire system, although it is obvious that the elements of the 


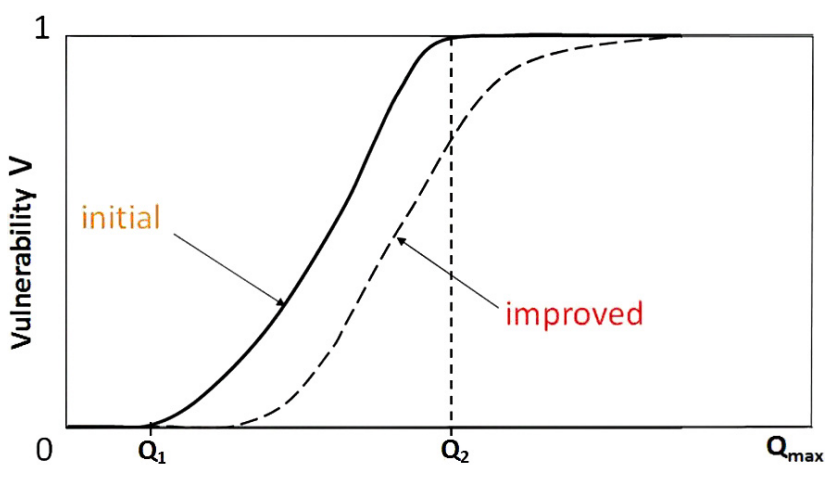

Figure 1. The vulnerability of a system (initial and improved) as a function of the magnitude of the phenomenon.

system may exhibit differential vulnerability. The vulnerability of a system exposed to a certain natural hazard is dependent mainly on the degree of exposure, the capability of the system to withstand, the magnitude of the phenomenon and the social factor which represents the responsiveness and the effectiveness of the people to deal with the abnormal conditions caused by the hazard occurrence. Last but not least, the resilience of the system can be also incorporated in the vulnerability concept.

In Eq. (3), it should be noted that the integration starts from zero, although in reality (Fig. 1) this starts from a certain positive threshold indicating a minimal protection. Also, the variance of risk is calculated in a similar way as in the case of the equation describing the variance of hazard.

In order to understand clearly the chain between hazard and risk and the proposed systemic approach, we present now an analogy from everyday life. A family (husband, wife and child) goes to the beach to swim on a bright hot summer day. Here, the danger to cause harm is the sun and its detrimental activity. If exposed without protection to the sun, any member of the family may run into dermatological problems. For this reason, the family stays under an umbrella which limits the activity of the sun and protects the members of the family to a great extent. However, the members cannot be protected totally from the sun's rays during their stay on the beach.

This analogy gives us a clear explanation of the terms related to risk assessment according to the proposed systemic approach. The members of the family are the elements of the system. Each element of the system has different susceptibility to harm, therefore its vulnerability towards the sun activity is different. The umbrella assists in the protection of the members, lowering their exposure, and therefore decreasing their vulnerability. The remaining part of the sun activity, which passes through the umbrella or reaches the members of the family through deflection and harms the members of the family, is the risk associated with the hazard event. Obviously, this is a snapshot of the hazard (a hazard episode) and the remaining risk. As mentioned earlier, both hazard and risk can be described by a time series related directly to the hazardous phenomenon, which is realised in various intensities and timescales. Therefore, the overall consequences on the elements of the system from several visits over the years to the beach can be assessed by the average risk.

Analogously, for flood risk assessment, the time series of flood events (e.g. hydrographs) threatening the flood-prone area represent the flood hazard, whereas the affected system is the area threatened by floods (e.g. a whole watershed or a part of it). The elements of the system are the squares of the grid of the entire domain - composite elements - or, in more detail, any item characterised by its type, its location in the area under study, and its initial value at risk. For example, an element of the latter characterisation could be a two-storey building with a basement (type), in a certain square of the city affected (location), whose value at risk is some thousands of euros (initial value at risk).

The simplest method for calculating the damage in each element is to use an appropriate depth-damage curve, which is tailored to the type of element and the specific location (FEMA, 1993, 2003). In a recent study on the dimensions of the elements in an urban area suffering from floods, it was concluded that, if bigger areas of land are taken as the elements of the system, the quantification of the damages and, therefore, the estimation of flood risk is more reliable (Pistrika, 2010).

In conclusion, the proposed paradigm for flood hazard and risk estimation proceeds as follows:

Step 1: Step 1 considers the various hydrographs produced for different return periods and the potentially inundated area with the maximum water depths theoretically estimated by the volume of flood without any losses. These inundation depths for each scenario (return period) are then used for the estimation of potential consequences. The theoretical consequences, which can be caused by these depths, represent the estimation of flood hazard corresponding to the return period in question.

Step 2: Step 1 refers to a totally unprotected area from floods. However, due to some natural and man-made protection measures and structures, the routing of the flood of each scenario produces different inundation depths (generally smaller than the previous ones), thus, corresponding to lower damages and losses. These more "realistic" damages and losses in appropriate units (e.g. monetary units) represent the flood risk of each scenario.

For illustration purposes, let us consider the abovementioned building as an element of the suffering system. The 100-yearly flood gives roughly an inundation depth of one metre which causes damage of EUR 50000 to a building. If the same flood is routed through the flood-prone area with all protection structures, using the appropriate data and routing packages, the maximum depth which is recorded for 
the building is $0.60 \mathrm{~m}$ which causes an estimated damage of EUR 35000 . Thus, the hazard of this event for this element of the system is EUR 50000 and the anticipated risk is EUR 35000 , leading to the value of 0.70 of the vulnerability function. The risk management plan in this case should be directed towards the measures and structures which can lower the vulnerability of the element, and most importantly, the vulnerability of the whole flood-prone area, not only for the certain event but for the entire time series of the hazardous flood phenomenon. For the identification of the really flood vulnerable areas and the prioritisation of schemes of protection measures, the average (annualised) risk of each area should be calculated as presented previously.

The above simplistic examples demonstrate the proposed new paradigm for analysing floods as natural hazards, assessing flood risk in the flood-prone areas and formulating plans for lowering their vulnerability. However, the implementation of this paradigm faces some severe difficulties. One of them is how we can, even roughly, estimate the damage and losses without taking into account any natural or man-made existing protection. The answer to this is that hazard damages can be roughly estimated since they do not play any important role in the final risk assessment. Even for the comparison of different flood-prone areas and the prioritisation of areas for action against floods, the average risk is the key determinant and can be assessed independently.

Another important drawback of the method (and any method based on loss/damage estimation), is the estimation of loss of life associated with the phenomenon and its transformation to units compatible to the losses and damages. This is still an open issue with no definite answer yet, although it has been addressed from various angles (Pistrika, 2010).

\section{The EU flood directive}

In the past, engineering studies would be conducted for flood-prone areas and, based on a certain probability scenario, reclamation measures and protection structures were usually proposed as the engineering view of protection. The aim was always to protect the flood-prone area from flooding, provided that future floods would not exceed the probability level of design of flood protection structures.

With the new EU flood directive 2007/60 (EC, 2007), there is a paradigm shift in the studies of floods. The studies are oriented towards the rationalisation of the procedure of flood risk mitigation measures. According to this innovative paradigm, flood scenarios are formulated corresponding to high, medium and low probability, and the associated risk (in terms of losses/damages expressed in monetary units) is evaluated. Further improvements are proposed if the anticipated loss/damage cost is higher than the proposed protection measures. That is to say that from "structural defence" based on a certain probability of exceedance we move to a balance of risk and measures. As one statesman put it, the new directive can be summarised by the slogan "we have to live with floods".

The new directive implementation is based on three consecutive steps: the preliminary delineation of flood-prone areas, the flood hazard maps, and the flood risk map resulting for each probability scenario. The flood hazard map shows the highest inundation water depths in the entire domain, whereas the flood risk map shows the damage/losses at each cell of the computational field in monetary units. From the above two maps, several improvement measures can be evaluated based on a clearly rational approach.

It should be stressed at this point that although the EU directive resembles the paradigm presented in the previous paragraphs, there are two major differences between the two procedures:

a. the flood hazard in the EU directive is not evaluated as the damage/loss level of the totally unprotected system, as it is the case for the proposed paradigm of this paper, but as the set of the highest inundation depths which can be recorded in all cells of the flood-prone area for the examined scenario;

b. the EU directive proposes only three levels for probability scenarios which should be tested. Therefore, information is derived only on the three proposed probability scenarios. In contrast, the paradigm proposed in this paper is based on the calculation of average risk, for which at least 5-6 probability level/return period scenarios should be tested (e.g. return periods 10, 25, 50, $100,500,1000$ years). This is because the level of damage/losses should be described covering the whole range of magnitudes of the phenomenon.

At a first glance, the implementation of the Flood Directive looks rather simple. However, in reality, it is very difficult to apply, mainly due to the large bulk of data required. Detailed topographic data, assets data, economic activities data, and many others should be available on GIS layers in order to be used both for hazard and risk maps. The critical point is that, in most of the cases, reliable and complete data are very seldom available and their collection is not always an easy task. Furthermore, this type of data is often of dynamic nature, influenced by a number of factors. Therefore, they are not totally reliable for supporting decisions on measures against floods, since they are not stationary.

Another critical point is how to transform the hazard map to the risk map. The only practical way so far is through depth-damage curves. That is, the damage is expressed as a 1-1 function of inundation depth. However, this type of curve should be derived specifically for the location in which it will be applied. There is a high possibility of error which somehow should be accounted for (Pistrika and Tsakiris, 2007).

Also damage/losses cannot be uniquely related to the highest simulated inundation depth at each cell from a certain flood episode. The damage/losses can be influenced by other 


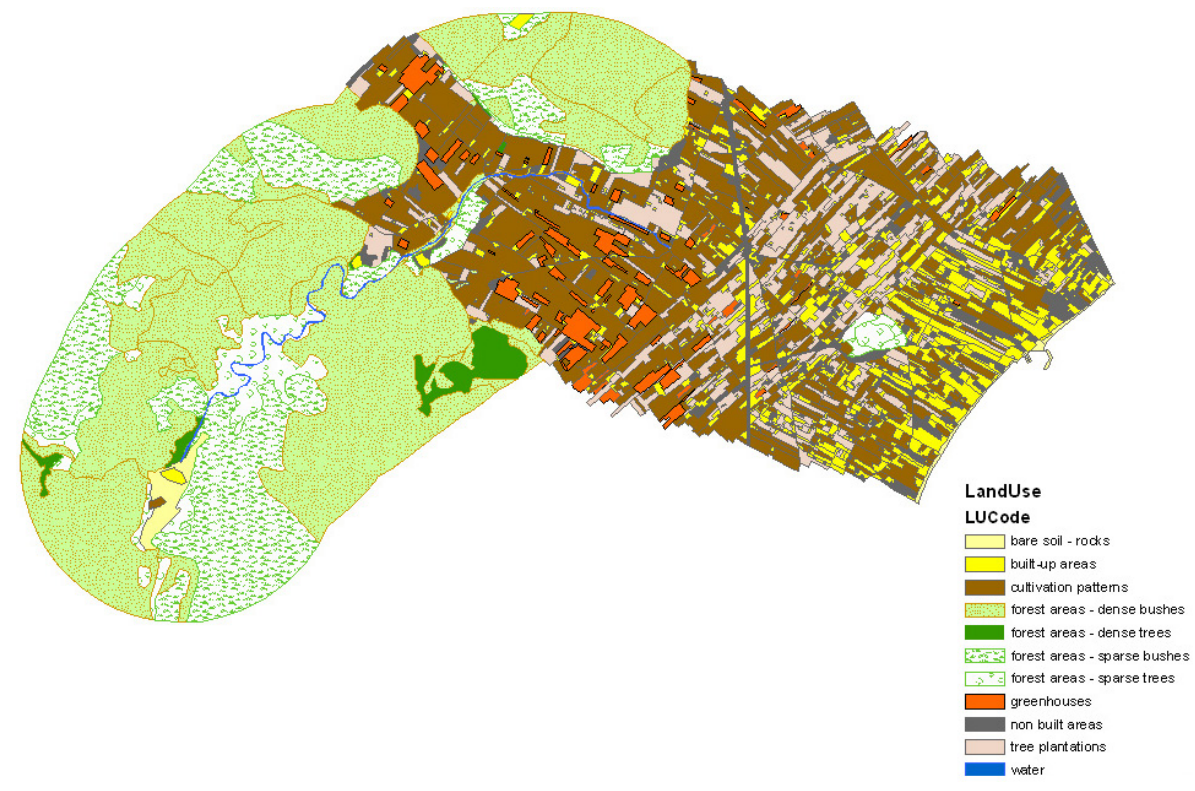

Figure 2. The land use map of Rapentoza watershed.

hydraulic parameters, such as water velocity for instance. Damage/losses can be direct or indirect, simultaneous or delayed, tangible or intangible. Therefore, the type of approach, based on the estimation of damage/losses as a unique function of the highest depth of water recorded in each cell, is very simplistic and may result in misleading conclusions.

Apart from the above criticism, the implementation of the flood directive by the member states is useful and will gradually assist in devising rational plans for the protection of the flood-prone areas.

The following are proposals for the improvement of the modelling of floods, particularly in mild and urban terrains. In these areas, the risk is generally higher, and therefore these areas deserve more detailed and careful analysis.

As an example for the implementation of the Flood Directive, the case of the Rapentoza watershed above the Marathon Gulf in Attica, Greece, is presented. The watershed has an area of $35 \mathrm{~km}^{2}$. On the main stream, a flood defence dam was built to protect from frequent floods the mild terrain downstream valley, which is a densely populated area with intense agricultural activities and a large number of greenhouses. In this area, there are also important monuments of cultural heritage which are also at risk.

In Figs. 2, 3 and 4, the land use map of the flood-prone area, the flood hazard map for the scenario of 100 years return period, and the flood risk map for the same scenario are presented, respectively. Eleven categories of land use are shown on the land use map (Fig. 2). The various tones of blue indicate corresponding classes of water depth (Fig. 3). Finally, the various colours in the map of Fig. 4 correspond to the related classes of total damage in monetary units. This application was made in the framework of the DISMA project
(Tsakiris et al., 2007). The tasks related to the production of flood hazard and risk maps are concisely presented in the flowchart of Fig. 5. As can be seen, the flowchart comprises three sections of calculations, one referring to geoinformation, the second to the formulation of scenarios and hydrologic and hydraulic computations, and the third to demographic data, economic activities and information on the important environmental sites and cultural heritage monuments. To some extent, the flowchart is self-explanatory. However, details of the application can be found in the final report of the DISMA project (Tsakiris et al., 2007).

\section{Flood modelling in urban areas with mild terrain}

For the implementation of the EU directive on floods (2007/60), various scenarios should be formulated based on the corresponding return periods (e.g. 10, 100 and 1000 years). Each scenario results in a design hydrograph, which is then routed through the hydrographic system of the area of interest. The inundated area is delineated and a time series of the most important determinants (e.g. water depth, velocity, etc.) of this unsteady phenomenon are recorded in the total number of cells of the physical domain.

For the most accurate modelling of each flood scenario, the most powerful tools should be used. Normally, 1-D modelling is practiced in order to reach practical results with low computational cost. However, in areas with mild terrain, this rather simplified approach can produce misleading results. Furthermore, additional complications are inserted into the modelling process, if there are obstacles in the computational field (e.g. buildings, bridges etc.). Therefore, in the areas of mild terrain, and particularly in built-up areas, a 


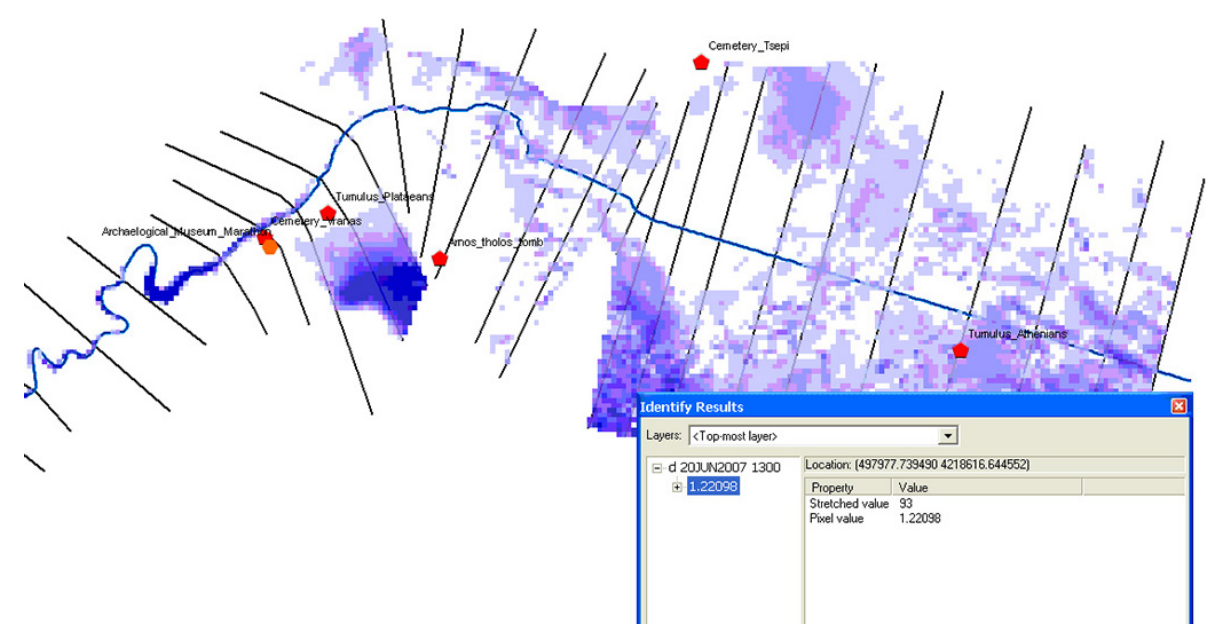

Figure 3. The flood hazard map of Rapentoza watershed for the scenario of $T=100$ years (blue colour indicates the inundation area).

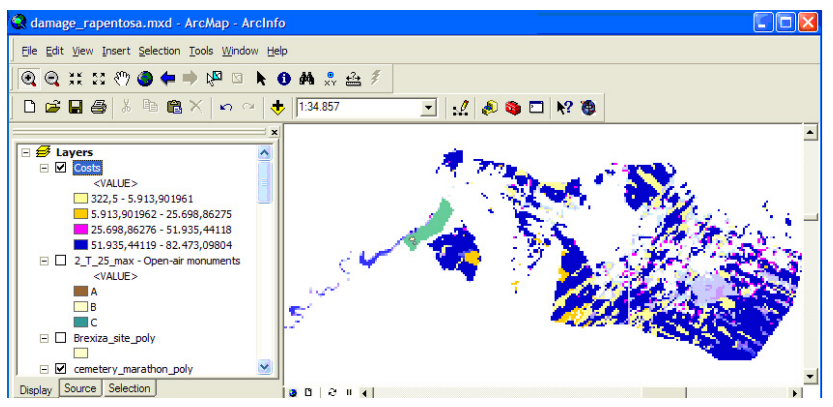

Figure 4. The flood risk map for the Rapentoza watershed for the scenario $T=100$ years (the colours indicate the various levels of damage in monetary units).

more comprehensive modelling approach should be adopted, e.g. 2-D and possibly 3-D models (Abderrezzak et al., 2008; Mignot et al., 2006; Ravagnani et al., 2009; Testa et al., 2007).

Several packages are already available for 2-D flood modelling. The most popular of them are MIKE 21, CCHE2D, TELEMAC-2D, ISIS-2d, SOBEK, TUFLOW, RiverFLO2D, and Infoworks-2D.

It is interesting to note that 3-D models are still very expensive to run, and the additional information they offer is not of great importance for the calculation of the impacts (Tsakiris and Bellos, 2014). Therefore, it seems that 2-D models are sufficient for this type of modelling. However, it should be stressed that modelling should be based on the fully dynamic approach and not on simplifications which are attractive but not appropriate. For instance, kinematic wave models can perform satisfactorily in steep areas with simple topography but fail to work accurately in mild terrains with complex topography.

One of the most comprehensive models recently constructed at the Centre for the Assessment of Natural Hazards and Proactive Planning of the National Technical University of Athens is the FLOW-R2D. Details of the model are given by Tsakiris and Bellos (2014). Here, only a brief description follows.

The model is based on the 2-D shallow water equations (2D-SWEs) with discretisation based on the two-step McCormack numerical scheme (McCormack, 1969). As is known, the McCormack scheme is explicit, and therefore stable, under the Courant-Friedrichs-Lewy condition (Szymkiewicz, 2010; Benedini and Tsakiris, 2013). The simulation of moving boundaries between wet and dry bed is achieved through a threshold of water depth which distinguishes wet and dry cells. Further, the model has shock capturing capabilities, and therefore, can describe discontinuities of the flow such as hydraulic jumps. Finally, a diffusion factor is incorporated in the model to diffuse oscillations which may be encountered during the numerical simulation. Quite recently, the model incorporated facilities to account for the buildings or other structures by using the proposed reflection boundary method (Bellos and Tsakiris, 2013).

After extensive testing, the model was applied to realworld applications with very satisfactory results. Figure 6 shows the results of the model application in the estuary of Spercheios River in Greece. Both maps of water depth $(h(\mathrm{~m}))$ and water velocities $\left(V\left(\mathrm{~m} \mathrm{~s}^{-1}\right)\right)$ are presented in Fig. 6 (Tsakiris and Bellos, 2014). In other applications of the model, representation of the built-up areas was given first priority. Figures 7 and 8 present the inundation maps resulting from the routing of a hydrograph through an urban area with buildings in aligned arrangement simulating an experimental setup (Bellos and Tsakiris, 2013).

\section{Critical points in the flood directive implementation}

Several critical technical points in the implementation of the flood directive, mainly in regard to data requirements, have 


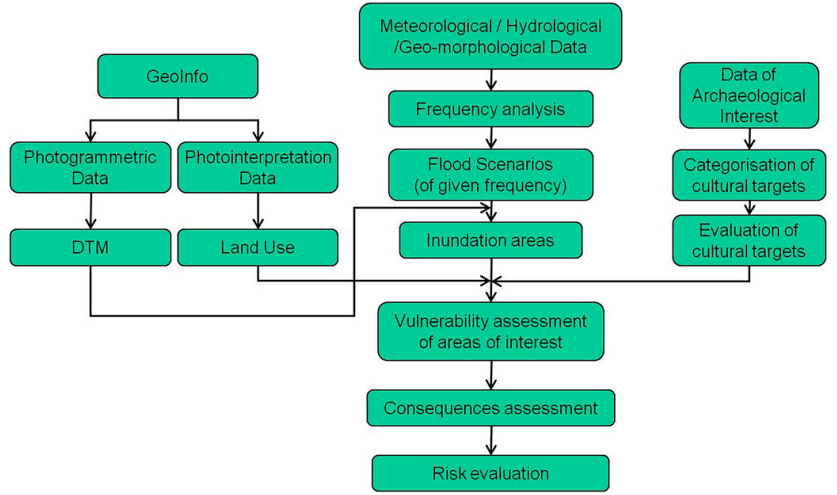

Figure 5. The flowchart of the procedure followed for the derivation of flood hazard and flood risk maps.

been highlighted by Tsakiris et al. (2009). From the points raised in the above paper, among others, the bivariate flood scenario should be emphasised. As is known, the key flood scenario variables are the flow and the volume. Therefore, by considering only the flow characteristics in the univariate analysis, we neglect the volume which may be the critical determinant for causing flood (Tsakiris and Spiliotis, 2013).

In the present paper, two additional concerns are pinpointed, although they are based on theoretical grounds and cannot be easily addressed through the implementation of the flood directive in practice. These two points are the "nonstationarity in flood engineering design" and the "decision on plans under uncertainty". Both topics are vast and cannot be comprehensively addressed in this paper. However, some fundamental discussion on these subjects is provided below. For a more thorough analysis of these subjects, the reader should consult specialised books (e.g. AghaKouchak et al., 2013).

For practical reasons, we adopt the following definition of "wide-sense stationarity". This type of stationarity is satisfied when neither the mean nor the autocorrelation change with time. Therefore, there is no interest in trends, seasonalities or cycles. In engineering design, if stationarity is satisfied, the return period for hydrological determinants is calculated.

Obviously, detecting and attributing trends in hydrological data is a complicated process, and often it is misled by the intrinsic climatic variability. There are several scientific methods to analyse nonstationarity such as testing for break points, spectral analysis, wavelet analysis, trend detection, estimation of time varying parameters, etc. However, in most of the cases, reliable data of long time series are not available, and therefore nonstationarity analysis may produce ambiguous results.

What remains from this very concise synopsis of the problem of nonstationarity is that in Flood Risk Management Plans, man-induced and climatic changes should be carefully
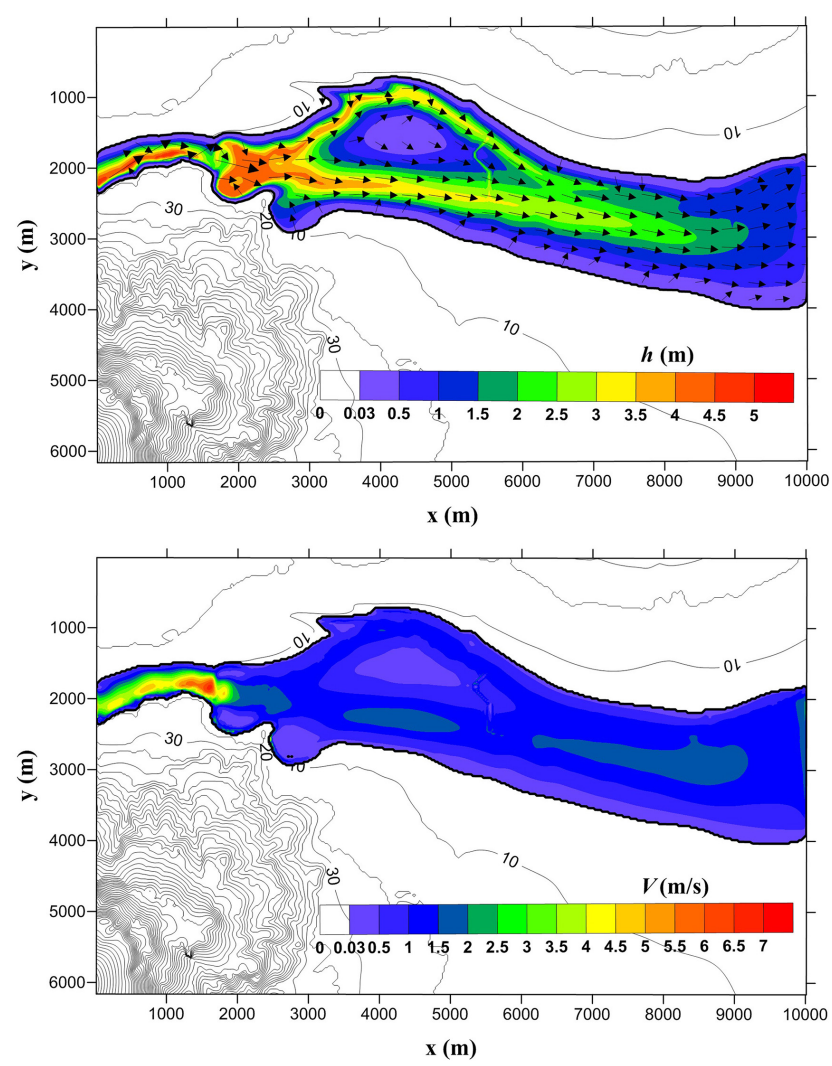

Figure 6. Snapshots from the application of FLOW-R2D in the estuary of Spercheios River with water depth and flow velocity, respectively.

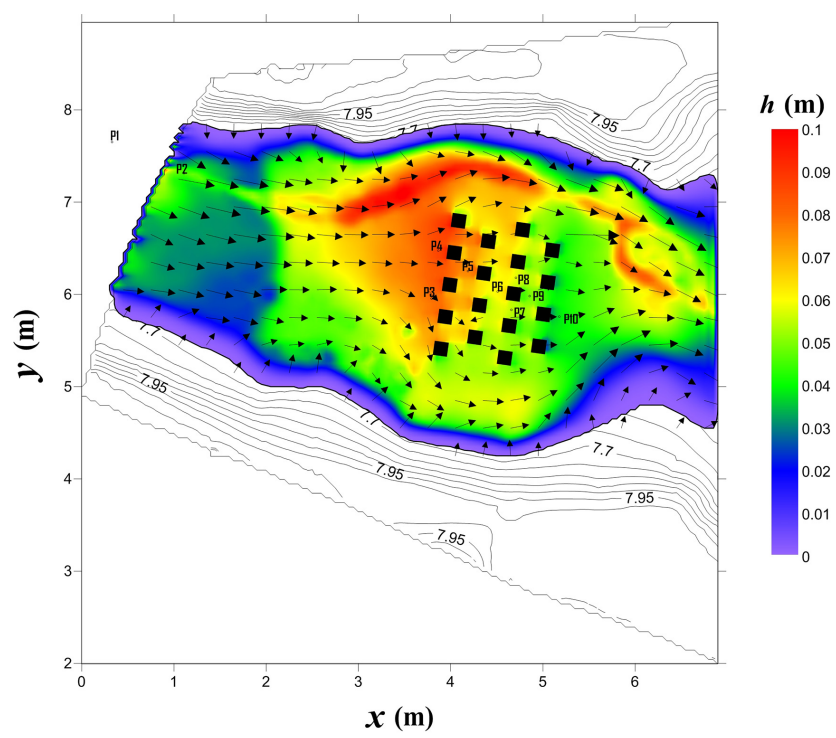

Figure 7. A snapshot of the distribution of inundation depths in an experiment with aligned buildings as produced by FLOW-RD2. 


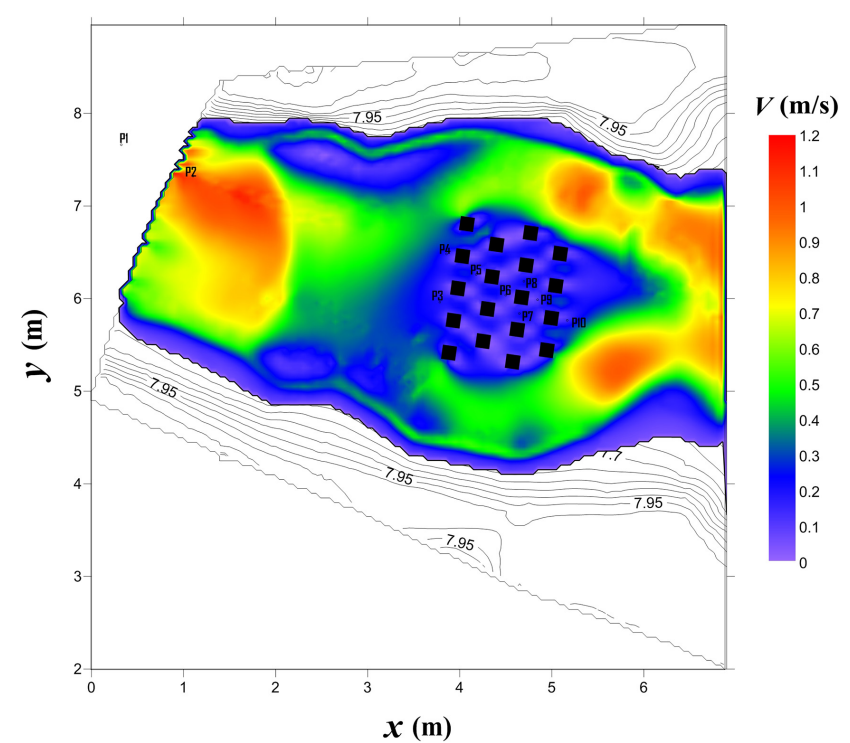

Figure 8. A snapshot of the distribution of velocities in an experiment with aligned buildings as produced by FLOW-RD2.

studied, adequately understood and considered in a broad sense.

Directly related to the problem of nonstationarity (due to man-induced and climatic changes) is the problem of uncertainty, which is embedded in all data and decisions concerning flood risk management. Methods for incorporating uncertainty into the decisions are many. Here, an attempt is made to present some of the most popular options to incorporate uncertainty into the design of structural and nonstructural measures for flood defence.

These methods are epigrammatically presented as follows.

- Sensitivity analysis: to evaluate the sensitivity of existing or planned infrastructure to expected variability. This can be phrased as "what level of change must happen to have a significant effect".

- Adaptive approach: to design with certain flexibility so that upgrades can be realised in the future.

- Scenario approach: to run precalibrated models with projected future conditions (which for climate change can be produced by downscaling of bias-corrected General Circulation Models (GCMs)).

- Spatial gradient: that is, to simulate the future conditions in an area which may resemble the present conditions of other areas.

- Revision of IDF curves: to revise the intensityduration-frequency curves of an area based on the analysis of long reliable time series of rainfall data.
- Empirical approaches: to design with higher return periods than those adopted so far, based on empirical observations.

\section{Concluding remarks}

In this overview paper, a new paradigm for the defence against floods, formulated on the basis of flood risk management, is presented. The new paradigm is based on the systemic approach and the rational sequence "hazardvulnerability-risk". Selection and prioritisation of reclamation measures are based on the average (annualised) flood risk which is calculated from a wide range of flood probability scenarios.

Further, the new European flood directive is presented in brief and it is concluded that, in general, it is in line with the proposed paradigm. However, in the flood directive, the reclamation measures are selected based on a limited range of flood probability scenarios. Sample applications of the directive are presented for illustration purposes. Also some critical points of its implementation are highlighted.

Emphasis is given to urban flood modelling and in particular to flood modelling in the flood-prone built-up areas in mild terrain. Two-dimensional fully dynamic models are proposed for the realistic simulation of flood evolvement in these areas.

Finally, the nonstationarity of flood events and the uncertainty of calculation of flood damage/losses are also discussed.

Acknowledgements. The paper, as an overview paper, was grounded on data and results from research projects and publications of the Centre for the Assessment of Natural Hazards and Proactive Planning of the Nat. Technical University of Athens, in which many other scientists took part. This is to acknowledge their contribution to the development of the paradigm and the examples presented in this paper.

Edited by: A. Loukas

Reviewed by: four anonymous referees

\section{References}

Abderrezzak, K., Paquir, A., and Mignot, E.: Modelling flash flood propagation in urban areas using a two-dimensional numerical model, Nat. Hazards, 50, 433-460, 2008.

AghaKouchak, A., Easterling, D., Hsu, K., Schubert, S., and Sorooshian, S. (Eds.): Extremes in a Changing Climate, 5 Water Science and Technology Library, Vol. 65, Springer, 423 pp., 2013.

Bellos, V. and Tsakiris, G.: Flood modelling in complex urban environments, in: Proceedings of the EWRA Conference, Porto, June 2013, 893-906, 2013. 
Benedini, M. and Tsakiris, G.: Water Quality Modelling for Rivers and Streams, Water Science 10 and Technology Library, Vol. 70, Springer, 288 pp., 2013.

European Council: EU Directive of the European Parliament and the European Council on the Assessment and Management of Flood Risks (2007/60/EU), 2007.

Guha-Sapir, D., Hargitt, D., and Hoyois, P.: Thirty Years of Natural Disasters 1974-2003: The Numbers. Centre for Research on the Epidemiology of Disasters, Presses Universitaires de Louvain (UCL), Brussels, 188 pp., 2004.

Hashimoto, T., Loucks, D., and Stedinger, J.: Reliability, resiliency, robustness and vulnerability criteria for water resource systems, Water Resour. Res., 18, 21-26, 1982.

FEMA: Flood insurance study guidelines and specifications for study contractors, Report 37, Washington DC, 1993.

FEMA: HAZUS: Multi-Hazard Loss Estimation Model Methodology - Flood Model, Washington DC, 2003.

McCormack, R. W.: The effect of viscosity in hypervelocity impact cratering, in: AIAA Hypervelocity Impact Conference, Cincinnati, 1969.

Mignot, E., Paquir, A., and Haider, S.: Modelling floods in a dense urban area using 2D shallow water equations, J. Hydrol., 327, 186-199, 2006.

Nicolosi, V., Cancelliere, A., and Rossi, G.: Drought risk analysis in water supply systems using genetic algorithms and Monte Carlo simulation, in: Proc. of EWRA Symposium "Water Resources Management: New Approaches and Technologies", Chania, Crete-Greece, 14-16 June 2007, 33-40, 2007.

Pistrika, A.: Estimation of Direct Flood Damage in Built-up Environments, Ph.D. thesis, Nat. Technical Univ. of Athens, School of Rural and Surveying Eng., 2010.

Pistrika, A. and Tsakiris, G.: Flood risk assessment: a methodological framework, in: Proc. of EWRA Symposium "Water Resources Management: New Approaches and Technologies", Chania (Greece), June 2007, 13-22, 2007.
Ravagnani, F., Pellegrinelli, A., and Franchini, M.: Estimation of urban impervious fraction from satellite images and its impact on peak discharge entering a storm sewer system, Water Resour. Manage., 23, 1893-1915, 2009.

Szymkiewicz, R.: Numerical Modelling in Open Channel Hydraulics, Water Science and Technology Library, Vol. 83, Springer, 419 pp., 2010.

Testa, G., Zuccala, D., Alcrudo, F., Mulet, J., and Soares-Frazao, S.: Flash flood flow experiment in a simplified urban district. 1, Hydraul. Res., 45, 37-44, 2007.

Tsakiris, G.: A paradigm for applying risk and hazard concepts in proactive planning: application to rainfed agriculture in Greece, in: Drought Management Guidelines - Technical Annex, edited by: Inglesias, A., Moneo, M., and Lopez, A., Franco (MEDROPLAN), 297-304, 2007a.

Tsakiris, G.: Practical Application of Risk and Hazard Concepts in Proactive Planning, European Water, 19/20, 47-56, 2007b.

Tsakiris, G. and Bellos, V.: A numerical model for two-dimensional flood routing in complex terrains, Water Resour. Manage., 28, 1277-1291, doi:10.1007/s11269-014-0540-3, 2014.

Tsakiris, G. and Spiliotis, M.: Dam-breach hydrograph modelling: an innovative semi-analytical approach, Water Resour. Manage. 27, 1751-1762, 2013.

Tsakiris, G., Pistrika, A., Klampanos, I., Laoupi, A., Ioannidis, Ch., Soile, S., and Georgopoulos, A.: DISMA - Disaster Management GIS with emphasis on cultural sites, Technical Report, Volume I - INTERREG IIIC - Sud Initiative and the Regional Operation Framework of NOE Programme - Patrimoine et prevention des risques naturels, Centre for the Assessment of Natural Hazards and Proactive Planning, Athens, Greece, 2007.

Tsakiris, G., Nalbantis, I., and Pistrika, A.: Critical Technical Issues on EU Flood Directive, European Water, 25/26, 39-51, 2009.

UNDRO: Mitigating Natural Disasters. Phenomena, Effects and Options, A Manual for Policy Makers and Planners, UN, NY, 1991. 